421

NEONATAL "HEPATIC RICKETS" IN PREMATURE INFANTS RECEIVING PARENTERAL ALIMENTATION (PA). MK Farrell, EJ Suchy, RC Tsang, JJ Steichen, JA Whitsett, JC Par tin, and WK Schubert. Univ. Cinti., Dept. Peds, Cincinnati. During a six month period, six premature infants (gestation 28 $31 \mathrm{wks}$, weight 790-1180 gm) developed cholestasis and severe met abolic bone disease whtle receiving parenteral alimentation. Spontaneous long bone fractures occurred in $3 / 6$. Infants received PA amino acid solutions for a mean of 4.5 wks (range 1-9); 4/ 6 received Intralipid. Hepatic dysfunction (direct hyperbilirubinemia, elevated transaminases) was first noted at a mean of 29 d (range 6-65) after initiation of PA. Osteopenia was evident by $x$-ray in all. Photon absorptiometry bone mineral analysis (BMA) was decreased in $3 / 4$ infants (Steichen, A.J. Roent. 126 1283). 25-OH vitamin D (25-OHD) was markedly reduced, < $10 \mathrm{ng} / \mathrm{m}$ in $6 / 6$; normal 20-80 $\mathrm{ng} / \mathrm{ml}$ (Belsey's). Serum Ca was normal in all and $P$ was $3.1-5.9 \mathrm{mg} / \mathrm{dl}$. One of six infants dfed of nonhepatic causes. The liver showed cholestasis with extramedullary hematopoesis, canalicular and hepatocellular stasis and minimal inflammation in two cases examined. Surviving infants were reated with 2500 units vit. $D_{3}$ p.o. and Ca $100 \mathrm{mg} / \mathrm{kg} / \mathrm{d}$. Fraccures healed in $3 / 3$; serum $25-0 H D$ levels normalized in $2 / 4$; serial BMA showed continued poor mineralization in $3 / 4$. Decreased serum 25-OHD may relate to decreased intake, absorption and hydroxylation of vitamin D and decreased enterohepatic circulation ff 25-OHD. "Hepatic Rickets" can occur in premature infants who levelop cholestasis while receiving parenteral alimentation and should be anticipated by serial measurement of serum $25-0 H$ vitchould be

\section{2 \\ IS HUMAN MILK THE BEST FOOD FOR LOW BIRTH WEIGHT} BABIES? Gilbert B. Forbes, University of Rochester Medical Center, Department of Pediatrics, Rochester, NY.

Carcass anolysis data show that the body content of $N$ and minerals throughout fetal life are linearly related to body weight when plotted on double log coordinates. Hence they conform to the allometric (heterogonic) equation $Q=b W^{k}$, where $Q$ is total body content and band $k$ are constants. When differentiated this becomes $d Q=b k W^{k-1} d W$, which says that $N$ and mineral accretions (dQ) are directly proportional to weight gain (dW) at any given body weight; and since $k$ differs from 1.0 the accretions corresponding to a given weight gain will a $T_{s o}$ vary with body weight. Nomograms (to be presented) based on these equations allow one to read off the retention of $N$ and minerals required to support normal body composition for a given weight and weight gain (maintenance needs are extra).

Application of these data to low birth weight babies indicates that human milk fed in usual amounts cannot meet the growth needs for $\mathrm{N}, \mathrm{Ca}, \mathrm{P}, \mathrm{Na}$ and $\mathrm{Fe}$ in the face of rapid growth. However, it does contain enough $\mathrm{K}, \mathrm{Cl}$ $\mathrm{Cu}, \mathrm{Mg}$ and $\mathrm{S}$.

For example, the $P$ content of $10 \mathrm{gm}$ of growth tissue in a $1000 \mathrm{gm}$ baby can be calculated from the above formula as follows: $d P=1.45 \times 1000^{0.164} \times 10(d W)=45 \mathrm{mg}$

$200 \mathrm{ml}$ human milk (i.e., $200 \mathrm{ml} / \mathrm{kg}$ ) will provide only $28 \mathrm{mg} \mathrm{P}$, while most commercial formulas will provide about $90 \mathrm{mg} \mathrm{P}$.

\section{BLOOD POLYAMINE DETERMINATIONS IN CHILDREN WITH} LIVER DAMAGE. A.D. Garnica, B.M. Rodgers, O.M.
Rennert, U. Florida College of Medicine, Dept. Rennert, U. Florida College of Medicine, Dept. Pediatrics and Surgery and U. Oklahoma, Dept. Pediatrics. Cell proliferation is associated with tissue polyamine putrescine, spermidine, and spermine after surgical or chemical liver infury, and have been interpreted to indicate hepatic regeneration. Whole blood polyamines reflect hepatic polyamine changes and were, therefore, measured serially in 16 infants and children with giant cell hepatitis (6), chronic active hepatitis (6), fructosemia. (1), and after hepatectomy (3). After hepatectomy the patients' spermidine levels increased 2.5-5.5 times normal, spermine 1.5-3.5. Similar elevations were seen initially in patients with hepatocellular injury, which returned to normal with biochemical resolution of their disease. Blood polyamines were normal-to-elevated in 6 patients with chronic active hepatitis, increased with steroid therapy and returned to normal with continued therapy, in only ! patient after biochemical remission. Among patients with active disease the mean blood spermidine was $18.87 \mathrm{~nm} / \mathrm{ml}(8.31 \pm 3.92)$, spermine $8.6 \mathrm{~nm} /$ ml $(4.98 \pm 3.12)$, spermidine:spermine $2.28(1.67 \pm 1.26)$. All patients demonstrated a peak spermidine:spermine ratio greater than 4 except two who expired with liver failure.

These data suggest that the course of hepatic injury and regeneration might be monitored through serial measurement of plood polyamines. A deficient polyamine response or persistent polyamine elevation may imply a poor prognosis.

424

MILK PROTEIN QUALITY AND QUANTITY: EFFECTS ON ORGANIC ACIDS IN LOW BIRTH WEIGHT INFANTS (LBWI). Gerald E. Gaull, Stephen R. Cohen, David K. Rassin, Bair L. Chlou, Kirsti Helnonen and Niels C. Raiha. Inst. Res. Menta Retard., S.I., N.Y. and Univ. Helsinki.

Urinary excretion of organic acids (OA) was determined by gas chromatography-mass spectrometry in 105 LBWI ( $\leq 2100 \mathrm{~g})$ randomly assigned to diets of: pooled human milk (HM) or one of four isocaloric formulas varying in prot. quant. ( 1.5 or $3.0 \mathrm{g \%}$ ) or qual. (whey:casein of $18: 82$ or $60: 40$ ). Differences were reported previously for pH, neg. base excess and both plasma and urine amino acid conc. as a function of both qual. and quant. Of diet prot. The TYR conc. was most increased of the amino acids, and its metabolites, $\mathrm{p}-\mathrm{OH}$-phenylacetic and $\mathrm{p}-\mathrm{OH}$-phenyllactle acids, are the most increased OA's. The OA metabolites of PHE were not increased in the infants fed the $3.0 \mathrm{~g} \%(18: 82)$ formul $\left(F_{4}\right)$ compared to those fed $\mathrm{HM}$; this finding correlated with the lesser effect of this formula on PHE compared with its effect on TYR. a-keto-y-methlolbutyrate, the a-keto acld of MET, was also excreted in $h$ igher concs. In the infants fed the $F_{4}$ formula compared to HM and correlated with similar

OAs were less affected or not different.

Thus, blochemical effects of different prot. qual. and quant. In formulas are seen in the $O A$ s as well as in the amino acids. These effects give further evidence of the need for caution in the use of formulas for LBWI in which prot. qual. and quan. have not been evaluated systematically. (Supported by the New York State Department of Mental Hyglene.)

425

INTESTINAL MATURATION: CALCIUM (Ca) TRANSPORT Ghishan and M. K. Younoszaj. College of Med. Univ. Our previous study suggested that the permeability of the intes tinal mucosa (PIM) to Ca was greater in suckling $(S)$ than in adolescent (A) rats (Pediat. Res. $11: 414,1977$ ). Definitive stud ies comparing PIM to $C a$ during development are not available. We compared transport of $\mathrm{Ca}$ in the proximal intestine of $\mathrm{S}$ (2 week old), $W$ ( 3 week old) and $A$ (6 week old) rats, using an in vivo recirculation perfusion technique. The perfusates were iso tonic $\mathrm{NaCl}$ solution containing either $0.4,1.6$ or 3.4 moles of $\mathrm{CaCl}_{2} / 1$ and Phenol Red $20 \mathrm{mg} / 1$. Ca transport rates (mean \pm S.E.; umoles $/ \mathrm{hr}$ per $\mathrm{g}$. wet wt.) from the different solutions were: 0.4 mmole/1 ( $S,-32.3 \pm 6.5 ; A,-0.7 \pm 0.2 ; p<.001) ; 1.6$ mmole $/ 1$ ( $S$, $-14.8 \pm 2.3 ; A, 1.8 \pm 0.4 ; p<.005) ; 3.4 \mathrm{mmole} / 1(S, 27.6 \pm 6.0 ; \mathrm{A}$, $3.3 \pm 0.9 ; p<.005)$. Transport $(T)$ rates in $W$ rats were intermedi-
ate between those of $S$ and $A$ rats $(-4.5 \pm 1.6,5.1 \pm 1.3,19.0 \pm 1.5$ ate between those of $S$ and $A$ rats $(-4.5 \pm 1.6,5.1 \pm 1.3,19.0 \pm 1.5$
respectively, from solutions containing $0.4,1.6$ or $3.4 \mathrm{mmole}$ $\mathrm{Ca} / 1)$. The 8 fold greater net absorption $(+\mathrm{T})$ rate at the high, and much greater net secretion $(-T)$ rate at the low luminal Ca concentrations in S than A rats indicated that PIM to Ca was greater in $S$ than $A$ rats. The reason for the age difference is not known. However, the process of maturation appears to decrease the PIM to $\mathrm{Ca}$, which continues into the post-weaning age If the age differences in $\mathrm{Ca}$ transport is also present in humans young infants, especially those with low birth weight, could be at risk of losing relatively large amounts of $\mathrm{Ca}$ into the intestinal lumen when dietary Ca intake stops abruptly.
426 GASTROINTESTINAL IRON ABSORPTION IS SULFHYORY HEAVY METALS. Patricia Pisciotto and Joseph $\mathrm{H}$. Graziano, Cornell Univers ity Medical College, New York. Spon. by

In iron deficiency, not only iron but lead and cadmium are hyperabsorbed. Al though the mechanism controlling iron absorption is still poorly defined, it has been demonstrated that cadmium absorption proceeds via the same mechanism as iron, and cadmium and iron competitively inhibit the absorption of each other. Since cadmium, arsenic and lead are notorious for binding to sulfhydry? groups, we have explored the role of sulfhydryl groups in the regulation of iron absorption.

In the rat, administration of the sulfhydryl blocker diethyl maleate (DEM; $0.6 \mathrm{ml} / \mathrm{kg}$ i.p.) 15 minutes prior to p.0. $59 \mathrm{Fe}$ administration reduced iron absorption to $20 \%$ of the control value; when ${ }^{59} \mathrm{Fe}$ was administered i.v., DEM had no effect on plasma iron clearance.

The administration of $1 \mathrm{mg} / \mathrm{kg}$ arsenic p.o. (as $\mathrm{As}_{2} \mathrm{O}_{3}$ ) dramatically inhibited the absorption of a test dose of $59 \mathrm{Fe}^{3}$ administered 3 hours later. Subsequent studies of mucosal glutathione metabolism indicate that GSH rapidly became bound to arsenic such that the effective GSH concentration was reduced. In response to the binding of arsenic to GSH, de novo synthes is of GSH occurred in the mucosal cell; when the GSH status returned to normal, normal iron absorption also resumed. These studies ascribe a role to GSH in iron absorption and explain why the heavy metals interfere with iron absorption. 